\title{
Anti-inflammatory drugs with therapeutic effects and drug regulators
}

\author{
Available online at www.hjhs.co.in \\ REVIEW ARTICLE \\ Prateek Paul ${ }^{*}$,a and Manvi ${ }^{\mathrm{b}}$ \\ ${ }^{\mathrm{a}}$ Department of Computational Biology and Bioinformatics, Jacob Institute of Biotechnology \\ and Bio-Engineering, Sam Higginbottom University of Agriculture, Technology and \\ Sciences, Prayagraj, Uttar Pradesh, India - 211007. \\ ${ }^{\mathrm{b}}$ Department of Molecular and Cellular Engineering, Jacob Institute of Biotechnology and \\ Bio-Engineering, Sam Higginbottom University of Agriculture, Technology and Sciences,
} Prayagraj, Uttar Pradesh, India - 211007

DOI $\underline{10.22270 / h j h s . v 6 i 3.106}$

\begin{abstract}
For prostaglandin production, the enzyme cyclooxygenase $(\mathrm{COX})$ is required. The two $\mathrm{COX}$ isoforms are constitutive COX-1 (which is responsible for physiological functions) and inducible COX-2 (involved in inflammation). COX inhibition explains both the medicinal (inhibition of COX-2) and negative effects (inhibition of COX-1) effects of non-steroidal anti-inflammatory medicines (NSAIDs). Nonsteroidal anti-inflammatory medicines (NSAIDs) act by blocking the enzyme cyclooxygenase (COX), which produces prostaglandins (PGs). To a greater or lesser extent, they share similar side effects, such as stomach and renal toxicity. According to a recent study, there are at least two COX isoenzymes. COX-1 is a naturally occurring enzyme that creates prostaglandins (PGs), which protect the stomach and kidneys. Aspirin's well-known anti-cancer impact could also be related to its influence on COX-2, which is expressed in this condition. As a result, selective COX-2 inhibitors may have new therapeutic potential as anticancer drugs, as well as in preventing premature labor and maybe reducing the progression of Alzheimer's disease.
\end{abstract}

Keywords: cyclooxygenase. NSAIDs, inflammation, colon cancer, anticancer agent.

\section{Introduction}

The Ebers papyrus, written some 3,500 years ago in ancient Egypt, advocated applying a decoction of dried myrtle leaves to the abdomen and back to relieve rheumatic pains in the womb. Hippocrates advised the juices of the poplar tree to cure eye disorders and the juices of willow bark to relieve childbirth pain and lower fever a thousand years later. Salicylates are present in all of these therapeutic treatments.

The use of extracts of salicylate-containing plants, particularly the bark of the willow tree (Salix alba and other members of the Salix species), in the treatment of fever, pain, and inflammation, gave rise to antiinflammatory analgesic medications. Inflammation is the body's natural response to harm. Enzyme activation, mediator release, fluid extravasation, cell migration, tissue disintegration, and repair are all part of the process. This paper will focus on the aspects of anti-inflammatory medicines that are affected, with a particular focus on the prostaglandin (PG) system. Phospholipase A2 activates this, releasing arachidonic acid, the cyclooxygenase substrate (COX or prostaglandin $\mathrm{H} 2$ [PGH2] synthase). Prostaglandin production rises as a result of this. COX is a dual-function enzyme that performs both cyclooxygenase and peroxidase functions.

Following the publishing of what were possibly the first clinical trials of willow bark extract for the treatment of agues or fever by the Reverend Edward Stone in the 17 th century, the popularity of these plant extracts grew during the 17th-19th centuries. In the early 19th century, the main active salicylate components were isolated, and in the mid-late 19th century, 
advances in chemistry in Europe and developments in the German chemical industry led to the synthesis of salicylic and acetylsalicylic acids, the latter of which was highly successful commercialised by Bayer AG as AspirinTM over 100 years ago.

In inflammatory circumstances ranging from experimental acute edema and sunburn to chronic arthritis, PGE2 is the most common eicosanoid found in humans. Because inflammation is one of the few settings in which PGE2 is a prominent product of COX, it's probable that the enzymatic route is directed towards this product by the inflammation process. A second enzyme, 5lipoxygenase, transforms arachidonic acid to leukotrienes, which are important asthma mediators. (1) PGE2 is a powerful dilator of vascular smooth muscle, which explains why acute inflammation causes vasodilation and erythema (redness). (2) Vasodilation increases blood flow through inflamed tissues, which exacerbates the edema induced by vascular permeabilityincreasing substances such bradykinin and histamine. (3) Inflammatory pain is also caused by PGE2, which works in concert with other mediators. PGE2 sensitizes receptors on afferent nerve endings to the effects of bradykinin and histamine without directly causing pain. (4) Furthermore, PGE2 is a potent pyretic agent, and its production in bacterial and viral infections, which is driven by the release of interleukin-1 (IL-1), adds to the associated fever. (5)

Inflammatory lesions have been found to contain a variety of COX products. PGFm, PGD2, prostacyclin (PGI2 as 6-oxo-PGF1 alpha) and thromboxane A2 (TXA2 [as TXB2]) are among them, but their concentrations are usually less than a fifth of those of PGE2. Prostacyclin, which is likewise a powerful vasodilator and a more potent hyperalgesic agent than PG2, is arguably the most important of these compounds in terms of inflammatory symptoms. Both PGEz and prostacyclin are believed to play a role in the development of inflammatory erythema and discomfort. (6)

\section{Discovery of NSAIDs}

Phenylbutazone (by JR Geigy, Basel, Switzerland) and later indomethacin (by Merck \& Co, Rahway, NJ, USA) were the earliest of the nonsteroidal antiinflammatory medications (NSAIDs), of which aspirin is now recognized as the progenitor. Initially, phenylbutazone was used in conjunction with antipyrine in the hopes of enhancing the latter's effects. However, it was discovered to have greater anti-inflammatory/analgesic activity than antipyrine and was successfully used for the treatment of arthritic and other painful inflammatory conditions for the better part of 30 years until its popularity waned after associations with life-threatening agranulocytosis and bone marrow suppression (still largely unproven today), upper respiratory infections, and other side effects.

\section{Mechanism of Action of Steroids in Inflammation}

Anti-inflammatory drugs known as corticosteroids are commonly used to treat rheumatologic disorders such as rheumatoid arthritis, lupus, and vasculitis (inflammation of the blood vessels). The drugs cortisone and prednisone are examples of specific corticosteroids. Corticosteroids diminish arachidonic acid release via inhibiting the activity of phospholipase A2. As a result, corticosteroids stop prostaglandins, thromboxane, and leukotrienes from forming. Anti-inflammatory hormones inhibit phospholipase A2 indirectly by releasing lipocortin 1, an inhibitory protein. (7)

Inhibiting phospholipase-induced edema in the rat paw, recombinant lipocortin 1 inhibits the release of eicosanoids from human tissues (8) and is a strong antiinflammatory drug. (9) In reaction to 
glucocorticoids, not all types of cells make lipocortin 1. Glucocorticoids are corticosteroids that bind to the glucocorticoid receptor, which is found in nearly every vertebrate animal cell. (10) The word "glucocorticoid" alludes to its role in glucose metabolism, adrenal cortex synthesis, and steroidal structure. Glucocorticoids have an effect on cells by binding to the glucocorticoid receptor. The activated glucocorticoid receptorglucocorticoid complex upregulates antiinflammatory protein expression in the nucleus (transactivation), while repressing proinflammatory protein expression in the cytosol (trans-repression) by preventing other transcription factors from the cytosol from entering the nucleus. (11)
Preferential

$\mathrm{COX}_{2}$ Inhibitor

Nimesulide, Aceclofenac,

Meloxicam, Etodolac
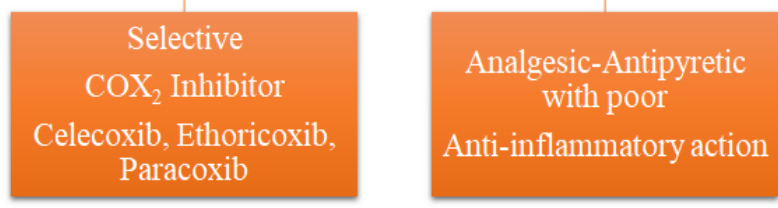

Figure 1. Chemical Classification of the NSAIDs

Another component of glucocorticoids' anti-inflammatory effect is their suppression of inducible cyclooxygenase- 2 (COX-2) synthesis. They bind to and activate cytoplasmic glucocorticoid receptors, which regulate the transcription of numerous key response genes such as COX-2 and nitric oxide synthase.

\section{Mechanism of Action of Non- Steroidal Anti-Inflammatory Agents}

It's hard to believe, but before 1971, no one knew how aspirin, the world's most widely used nonprescription medicine, worked. Since the active principle of willow bark was identified in 1876, the pharmacologic effects of aspirin and other nonsteroidal anti-inflammatory medicines (NSAIDs) have been known. (12) Aspirin inhibits $\mathrm{COX}$ by causing irreversible acetylation of the cyclooxygenase component, leaving the enzyme's peroxidase activity unchanged (13) NSAIDs such as indomethacin and ibuprofen, in contrast to aspirin's irreversible action, generate reversible COX inhibition by competing with the enzyme's substrate, arachidonic acid, for the active site. (14)

All of the activities of aspirin-like medications can be explained by inhibiting prostaglandin production. They inhibit the pathological overproduction of prostaglandins, which lead to inflammation (therapeutic actions) and the physiological creation of prostanoids (which results in the characteristic side effects). Aspirin's ulcerogenic potential stems from its reduction of prostacyclin synthesis, which is a key cytoprotective component of the gastric mucosa. (15) Experimental stomach ulcers can be reversed or prevented with the administration of several prostaglandins 
(16), and some of the recently produced prostaglandin derivatives are now available for clinical usage. Furthermore, NSAIDs' ability to erode the stomach mucosa is linked to their ability to suppress COX.

NSAIDs have been shown to decrease prostaglandin synthesis in a range of cell types and tissues, ranging from whole animals and humans to microsomal enzyme preparations. The concentration of a PGEz-like molecule in the synovial fluid of rheumatoid arthritis patients, for example, is around $20 \mathrm{ng} / \mathrm{ml}$. This falls to zero in patients on aspirin, providing clinical evidence of the drug's influence on prostaglandin synthesis. (17) Several inhibitor classes have been found (18), with at least 12 key chemical series known to have direct effects on prostaglandin synthesis. (19)

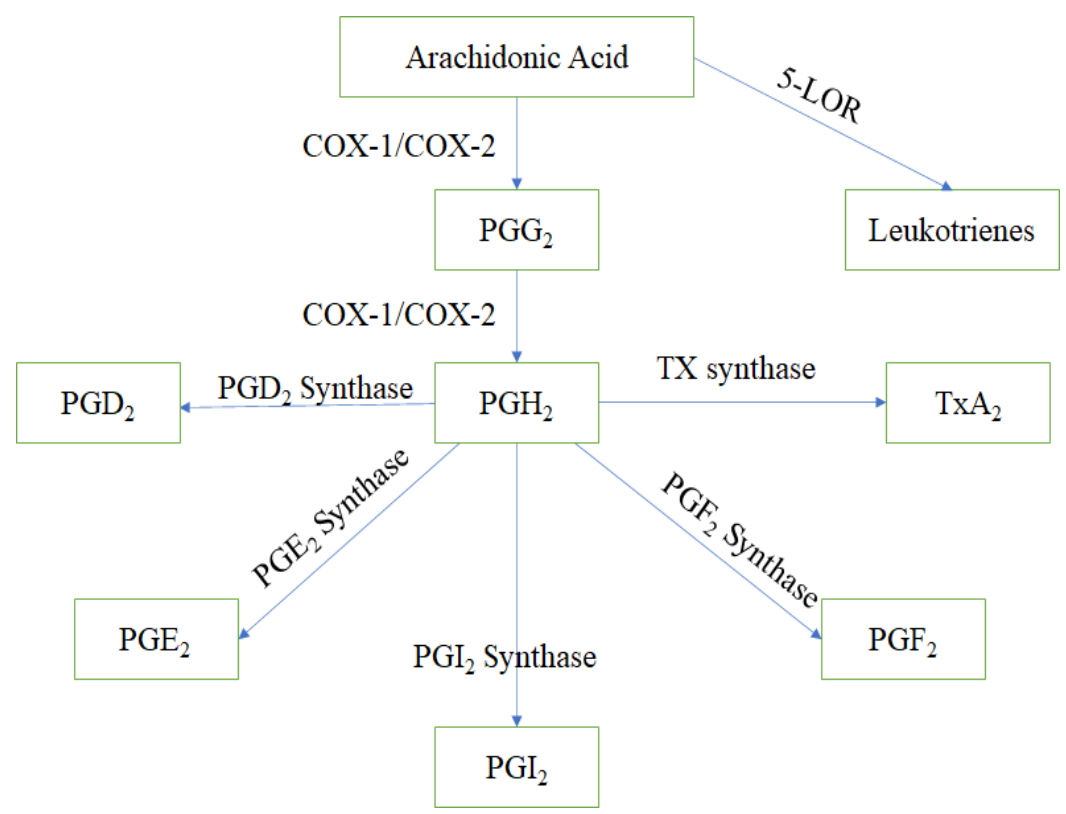

Figure 2. Process involved in production of prostaglandins and leukotrienes

\section{A Second Cyclooxygenase Enzyme has Been Found}

Needleman and colleagues discovered that bacterial endotoxin significantly boosted COX activity in human monocytes in vitro (20) and mice peritoneal macrophages in vivo. $(21,22)$ Dexamethasone inhibited this rise, which was linked to the creation of new COX protein. An inducible synthase was discovered a year or so later as an unique isoform of cyclooxygenase (COX-2) encoded by a different gene than the constitutive enzyme (COX-1). (23)

\section{Cyclooxygenase-1}

Cyclooxygenase- 1 is an enzyme that speeds up the creation of chemical messengers known as prostaglandins in several parts of the body, including the stomach, kidneys, and inflammatory sites. Prostaglandins encourage the formation of a protective natural mucus lining in the stomach. They also interact within specific cells that control inflammation and other processes. The activity of cyclooxygenase has long been examined in ram seminal vesicles, and a homogenous, enzymatically active COX was isolated in 1976. (24)

COX-1 is expressed ubiquitously in most tissues and serves as a "housekeeper" by synthesizing prostaglandins that regulate normal cell activity (in the given figure 3 ). The enzyme's concentration is largely steady, however minor increases in expression of two to fourfold can occur in response to hormone or growth factor stimulation. (25) 


\section{Physiological Stimulus}

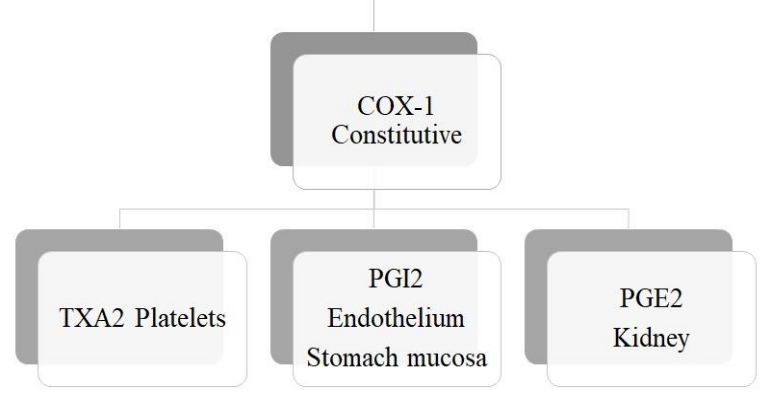

Inflammatory Stimulus

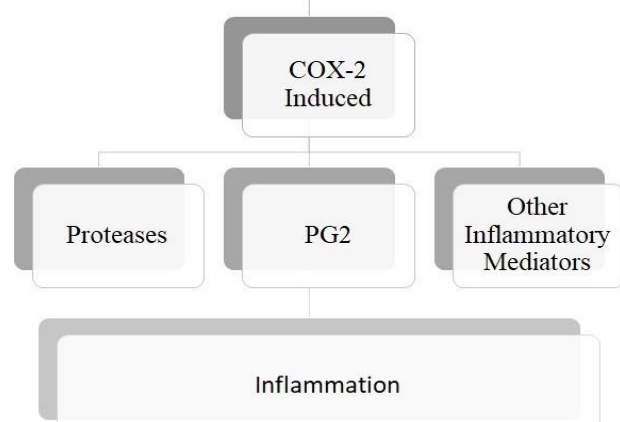

Figure 3. Relationship between the pathways leading to the generation of prostaglandins by COX-1 and COX-2.

\section{Cyclooxygenase-2}

COX-2 protein levels rise along with the overproduction of prostaglandins in numerous cells and tissues during chronic inflammation. The COX-2 gene is part of a group of main response genes that includes the inducible nitric oxide synthase gene, which is triggered during inflammation and cell proliferation. (26) Cox-2 catalyzes the conversion of arachidonic acid to prostaglandins and is an inducible type of cyclo-oxygenase. TNF and EGF can activate Cox-2, which is produced by inflammatory cells like macrophages.

\section{Cyclooxygenase-2 Selective Inhibition}

NSAIDs differ in the severity of their adverse effects at anti-inflammatory doses, although having equivalent degrees of anti-inflammatory efficacy in the clinic. When only one COX was known, this was impossible to explain. The discrepancies in anti-inflammatory activity of aspirin and salicylate, as well as the mechanism of action of acetaminophen, were other aspects that remained unsolved until the discovery of COX-2 (paracetamol).

In certain cell lines, salicylate has only about half the effectiveness of aspirin in suppressing COX-2. This profile is consistent with salicylate's lack of stomach irritation (27) and its lack of platelet activity (COX-1). (28) Salicylate appears to be active exclusively in whole cells, therefore the reduction of COX activity could be attributable to a metabolite.

Acetaminophen is an antipyretic and analgesic drug with limited antiinflammatory properties. Furthermore, it shows only sporadic efficacy against most COX preparations, but is much more effective at reducing prostaglandin synthesis in the brain. (29) Perhaps the brain enzyme is a third isoform of cyclooxygenase, COX-3, for which no specific inhibitors have been discovered.

COX-1 and COX-2 have different functions.

\section{GI Tract (Gastrointestinal Tract)}

Endogenously generated prostacyclin and prostaglandin E2 (PGE2), which inhibit gastric acid output and exert a direct vasodilator action on the arteries of the gastric mucosa, are primarily responsible for prostaglandins' "cytoprotective" function in preventing stomach erosions and ulceration.

COX-I produces protective prostaglandins in most species, including humans, while (30) discovered modest amounts of COX-2 in the normal rat stomach. $\mathrm{COX}-2$ is expressed in Helicobacter pylori-infected human stomach mucosa and ulcerative 
colitis. (31) In mice and rats, COX-2 is also expressed in the periphery of stomach ulcers.

\section{Kidney}

Vasodilator prostaglandins are required for the maintenance of kidney function in both animal models of disease and individuals with congestive heart failure, liver cirrhosis, or renal insufficiency. When prostaglandin synthesis is lowered by NSAIDs, these patients are at risk of renal ischemia. PGE2 and prostacyclin are mostly synthesized by COX-I, albeit low quantities of COX-2 mRNA have been detected. (32) Following salt shortage, COX-2 expression in the macula densa is also upregulated. The renin-angiotensin system may be driven by COX-2 expression.

\section{The Central Nervous System (CNS)}

COX-1 is located in neurons throughout the brain, but it is most numerous in the forebrain, where prostaglandins are thought to play a role in complex integrative activities like autonomic nervous system control and sensory processing. Pyogenic chemicals like LPS, interleukin I (IL-I), or tumor necrosis factor (TNF) activate COX-2 mRNA in brain tissue and cultured glial cells. (33) However, without prior stimulation by pro-inflammatory stimuli, low quantities of COX-2 protein and COX-2 mRNA have been found in forebrain neurons. COX-2 mRNA is also found in the spinal cord of normal rats, suggesting that it is involved in the processing of nociceptive stimuli. (34)

\section{System of Reproduction}

In fetal hearts, kidneys, lungs, and brains, as well as the decidual lining of the uterus, COX-1 expression is substantially higher than COX-2 expression. $(35,36)$ COX-I-produced prostaglandins appear to be critical for fetuses' survival during parturition, as the majority of children born to homozygous COX-1 knockout mice do not survive. (37) COX-2 induction is involved in ovulation and is a definite trigger for parturition (38), resulting in PGF2a release and uterine smooth muscle contractions.

\section{Endothelium}

Prostacyclin is an anti-aggregatory and vasodilator produced by endothelial cells. They certainly contain COX-I, but (39), employing the particular COX-2 inhibitor celecoxib, reported that celecoxib significantly reduced urine excretion of the prostacyclin metabolite at doses up to 800 $\mathrm{mg}$ in volunteers. They came to the conclusion that COX-2 is increased in circulating endothelial cells, most likely as a result of laminar shear stress. (40)

\section{Ratios of COX-2 to COX-1}

The differences in pharmacology of the two enzymes underline the significance of discovering the inducible COX-2. (41) COX-2 inhibitors such as aspirin, indomethacin, and ibuprofen are substantially less effective than COX-1 inhibitors. (42) Indeed, the NSAIDs that cause the most stomach damage are those that inhibit COX-I the most, such as aspirin, indomethacin, and piroxicam. (43) Because NSAIDs suppress COX-2, they are used to treat inflammation. The differences in the adverse effects of NSAIDs at their anti-inflammatory levels are explained by the range of actions of NSAIDs against COX-I compared to COX-2. Anti-inflammatory drugs with a high potency against COX-2 and a low COX-2/COX-1 activity ratio have substantial anti-inflammatory activity with little stomach and kidney adverse effects. In anti-inflammatory doses, piroxicam and indomethacin showed substantial gastrointestinal toxicity. These medications are substantially more effective against COX-1 than COX-2. (44)

\section{Selective COX-2 Inhibitors' Potential Therapeutic Applications}

Premature Birth 
During labor, prostaglandins cause uterine contractions. NSAIDs, such as indomethacin, postpone premature labor by reducing prostaglandin production, but they also cause the ductus arteriosus to close early and limit urine output by the fetal kidneys (Sawdy et al. 1997). Because mRNA for COX-2 increases dramatically in the amnion and placenta shortly before and after the commencement of labor (Gibb and Sun, 1996), the delay in the delivery process is most likely due to inhibition of COX-2, whereas the side effects on the fetus are attributable to inhibition of COX-1.

\section{Colon Cancer}

Epidemiological studies have found a substantial association between aspirin consumption and a lower risk of colon cancer. (45, 46) Sulindac also reduced prostaglandin synthesis and adenomatous polyp regression in 11 of 15 patients with familial adenomatous polyposis (FAP), a syndrome in which many colorectal polyps form spontaneously and proceed to malignancies. COX-2 (but not COX-I) is significantly expressed in human and animal colon cancer cells, as well as in human colorectal adenocarcinomas, indicating that COX activity is involved in the process leading to colon cancer. (47, 48)

Alzheimer's disease is a type of dementia that affects people.

Because there is no animal model of Alzheimer's disease, the link between COX and the disease has been established primarily in epidemiology. A number of studies have found that those who take NSAIDs as anti-inflammatory medication had a lower risk of Alzheimer's disease. (49-51). It's likely that the aspirin dose was too low to have an anti-inflammatory impact. The protective effect of NSAIDs is in line with findings of inflammatory activity in Alzheimer's disease pathogenesis. COX-2 has a lot of interest in Alzheimer's disease, and (52) found
COX-2 expression in the frontal cortex of Alzheimer's patients' brains.

\section{Conclusions}

Industrial screening programs discovered selective COX-2 inhibitors as strong NSAIDs with low toxicity in the stomach and kidneys even before the COX-2 enzyme was identified, employing models of chronic inflammation in conjunction with models of gastric injury. The evidence that selective COX-2 inhibitors will have considerably decreased side effects is strong, both in animal experiments and in clinics. Antiinflammatory therapy will benefit greatly from selective COX2 inhibitors. They are unlikely to be more effective antiinflammatory medicines than traditional NSAIDs, but they will have the significant benefit of being safer and more well tolerated. Meloxicam's clinical findings already suggest that it has enhanced safety and tolerability, despite the fact that it still has some COX-I action. In the future, these medications may be used to prevent colon cancer, Alzheimer's disease, and premature labor, in addition to their positive effects in inflammatory illnesses.

\section{Acknowledgements}

The authors are grateful to the Jacob Institute of Biotechnology and BioEngineering, Sam Higginbottom University of Agriculture, Technology and Sciences, Prayagraj for giving proper guidance and knowledge so that the author was able to build concepts and motivation for writing this paper.

Financial Disclosure statement: The author received no specific funding for this work.

\section{Conflict of Interest}

The authors declare that there is no conflict of interest regarding the publication of this article.

\section{References}

1. Murphy RC, Hammarström S, Samuelsson B. Leukotriene C: a slow-reacting substance from 
murine mastocytoma cells. Proc Natl Acad Sci U S A. 1979 Sep;76(9):4275-9. doi: 10.1073/pnas.76.9.4275. PMID: 41240; PMCID: PMC411556.

2. Solomon LM, Juhlin L, Kirschenbaum MB. Prostaglandin on cutaneous vasculature. J Invest Dermatol. 1968 Oct;51(4):280-2. PMID: 5676860.

3. Williams TJ, Peck MJ. Role of prostaglandinmediated vasodilatation in inflammation. Nature. 1977 Dec 8;270(5637):530-2. doi: 10.1038/270530a0. PMID: 593374.

4. Ferreira SH. Prostaglandins, aspirin-like drugs and analgesia. Nat New Biol. 1972 Dec 13;240(102):200-3. doi: 10.1038/newbio240200a0. PMID: 4629913.

5. Saxena PN, Beg MM, Singhal KC, Ahmad M. Prostaglandin-like activity in the cerebrospinal fluid of febrile patients. Indian J Med Res. 1979 Sep;70:495-8. PMID: 535962.

6. Higgs EA, Moncada S, Vane JR. Inflammatory effects of prostacyclin (PGI2) and 6-oxoPGF1alpha in the rat paw. Prostaglandins. 1978 Aug;16(2):153-62. doi: 10.1016/00906980(78)90018-7. PMID: 360302.

7. Wallner BP, Mattaliano RJ, Hession C, Cate RL, Tizard R, Sinclair LK, Foeller C, Chow EP, Browing JL, Ramachandran KL, et al. Cloning and expression of human lipocortin, a phospholipase A2 inhibitor with potential antiinflammatory activity. Nature. 1986 Mar 612;320(6057):77-81. doi: 10.1038/320077a0. PMID: 2936963.

8. Cirino G, Flower RJ. Human recombinant lipocortin 1 inhibits prostacyclin production by human umbilical artery in vitro. Prostaglandins. 1987 Jul;34(1):59-62. doi: 10.1016/0090-6980(87)90262-0. PMID: 2961007.

9. Cirino G, Peers SH, Flower RJ, Browning JL, Pepinsky RB. Human recombinant lipocortin 1 has acute local anti-inflammatory properties in the rat paw edema test. Proc Natl Acad Sci U S A. 1989 May;86(9):3428-32. doi: 10.1073/pnas.86.9.3428. PMID: 2470103; PMCID: PMC287146.

10. Pelt AC. Glucocorticoids: effects, action mechanisms, and therapeutic uses. Hauppauge, N.Y.: Nova Science. 2011; ISBN 978-1617287589.

11. Rhen T, Cidlowski JA. "Antiinflammatory action of glucocorticoids--new mechanisms for old drugs". The New England Journal of Medicine. Oct 2005; 353 (16): 1711-23. doi:10.1056/NEJMra050541

12. Buchanan WW, Kean WF. The treatment of acute rheumatism by salicin, by T.J. Maclagan--The Lancet, 1876. J Rheumatol. 2002 Jun;29(6):1321-3. PMID: 12064852.
13. Van Der Ouderaa FJ, Buytenhek M, Nugteren DH, Van Dorp DA. Acetylation of prostaglandin endoperoxide synthetase with acetylsalicylic acid. Eur J Biochem. 1980 Aug;109(1):1-8. doi: 10.1111/j.14321033.1980.tb04760.x. PMID: 6773769.

14. Vane JR, Flower RJ, Botting RM. History of aspirin and its mechanism of action. Stroke. 1990 Dec;21(12 Suppl):IV12-23. PMID: 2124385.

15. Miller TA. Protective effects of prostaglandins against gastric mucosal damage: current knowledge and proposed mechanisms. Am J Physiol. 1983 Nov;245(5 Pt 1):G601-23. doi: 10.1152/ajpgi.1983.245.5.G601. PMID: 6195926.

16. Robert A, Hanchar AJ, Lancaster C, Nezamis JE. Prostacyclin inhibits enteropooling and diarrhea. In: Vane JR, Bergstrom S, eds. Prostacyclin. Raven Press, New York; 1979.

17. Higgs GA, Vane JR, Hart FD, Wojtulewski JA. Effects of anti-inflammatory drugs on prostaglandins in rheumatoid arthritis. In: Robinson HJ, Vane JR, eds. Prostaglandin synthetase inhibitors. Raven Press, New York; 1988.

18. Flower RJ. Drugs which inhibit prostaglandin biosynthesis. Pharmacol Rev. 1974 Mar;26(1):33-67. PMID: 4208101.

19. Vane JR. Inhibition of prostaglandin synthesis as a mechanism of action for aspirin-like drugs. Nat New Biol. 1971 Jun 23;231(25):232-5. doi: 10.1038/newbio231232a0. PMID: 5284360.

20. Fu JY, Masferrer JL, Seibert K, Raz A, Needleman P. The induction and suppression of prostaglandin $\mathrm{H} 2$ synthase (cyclooxygenase) in human monocytes. J Biol Chem. 1990 Oct 5;265(28):16737-40. PMID: 2120205.

21. Masferrer JL, Zweifel BS, Seibert K, Needleman P. Selective regulation of cellular cyclooxygenase by dexamethasone and endotoxin in mice. J Clin Invest. 1990 Oct;86(4):1375-9. doi: 10.1172/JCI114850. PMID: 2120289; PMCID: PMC296874.

22. Fu JY, Masferrer JL, Seibert K, Raz A, Needleman P. The induction and suppression of prostaglandin $\mathrm{H} 2$ synthase (cyclooxygenase) in human monocytes. J Biol Chem. 1990 Oct 5;265(28):16737-40. PMID: 2120205.

23. Xie WL, Chipman JG, Robertson DL, Erikson RL, Simmons DL. Expression of a mitogenresponsive gene encoding prostaglandin synthase is regulated by mRNA splicing. Proc Natl Acad Sci U S A. 1991 Apr 1;88(7):26926. doi: 10.1073/pnas.88.7.2692. PMID: 1849272 ; PMCID: PMC51304. 
24. Hemler M, Lands WE. Purification of the cyclooxygenase that forms prostaglandins. Demonstration of two forms of iron in the holoenzyme. J Biol Chem. 1976 Sep 25;251(18):5575-9. PMID: 823151.

25. DeWitt DL. Prostaglandin endoperoxide synthase: regulation of enzyme expression. Biochim Biophys Acta. 1991 May 8;1083(2):121-34. doi: 10.1016/00052760(91)90032-d. PMID: 1903657.

26. Ryseck R. Raynoscheck C. Macdonald-Bravo H, Dorfman K. Bravo R. Identification of an immediate early gene, PGHs-6. whose protein product has prostaglandin synthase cyclooxygenase activity. Cell Growth Differ; 1992.

27. Whittle BJ, Higgs GA, Eakins KE, Moncada S, Vane JR. Selective inhibition of prostaglandin production in inflammatory exudates and gastric mucosa. Nature. 1980 Mar 20;284(5753):271-3. doi: 10.1038/284271a0. PMID: 6767192.

28. Vargaftig BB. Salicylic acid fails to inhibit generation of thromboxane A2 activity in platelets after in vivo administration to the rat. J Pharm Pharmacol. 1978 Feb;30(2):101-4. doi: $\quad$ 10.1111/j.2042-7158.1978.tb13171.x. PMID: 24092.

29. Flower RJ, Vane JR. Inhibition of prostaglandin synthetase in brain explains the anti-pyretic activity of paracetamol (4acetamidophenol). Nature. 1972 Dec 15;240(5381):410-1. doi: 10.1038/240410a0. PMID: 4564318.

30. Brideau C, Kargman S, Liu S, Dallob AL, Ehrich EW, Rodger IW, Chan CC. A human whole blood assay for clinical evaluation of biochemical efficacy of cyclooxygenase inhibitors. Inflamm Res. 1996 Feb;45(2):6874. doi: 10.1007/BF02265118. PMID: 8907587.

31. Ford-Hutchinson AW. New highly selective COX-2 inhibitors. In: Vane J, Botting J, editors. Selective COX-2 Inhibitors. Pharmacology, Clinical Effects and Therapeutic Potential. London: Kluwer Academic Publishers and William Harvey Press. 1998;117-25.

32. Mitchell JA, Akarasereenont P, Thiemermann C, Flower RJ, Vane JR. Selectivity of nonsteroidal antiinflammatory drugs as inhibitors of constitutive and inducible cyclooxygenase. Proc Natl Acad Sci U S A. 1993 Dec 15;90(24):11693-7. doi: 10.1073/pnas.90.24.11693. PMID: 8265610; PMCID: PMC48050.

33. Cao C, Matsumura K, Yamagata K, Watanabe Y. Cyclooxygenase-2 is induced in brain blood vessels during fever evoked by peripheral or central administration of tumor necrosis factor. Mol Brain Res. 1998; 56:45-56

34. Beiche F, Brune K, Geisslinger G, GoppeltStruebe M. Expression of cyclooxygenase isoforms in the rat spinal cord and their regulation during adjuvant-induced arthritis. Inflamm Res. 1998 Dec;47(12):482-7. doi: 10.1007/s000110050362. PMID: 9892042.

35. Bennett $P$, Slater D . COX-2 expression in labor. In: Vane J, Botting J, Botting R (eds) Improved non-steroid anti-inflammatory drugs. COX-2 enzyme inhibitors. Kluwer Academic, Lancaster. 1996; pp 167-188

36. Gibb W, Sun M. Localization of prostaglandin $\mathrm{H}$ synthase type 2 protein and mRNA in term human fetal membranes and decidua. J Endocrinol. 1996 Sep;150(3):497-503. doi: 10.1677/joe.0.1500497. PMID: 8882169.

37. Langenbach R, Morham SG, Tiano HF, Loftin CD, Ghanayem BI, Chulada PC, Mahler JF, Lee CA, Goulding EH, Kluckman KD, Kim HS, Smithies O. Prostaglandin synthase 1 gene disruption in mice reduces arachidonic acidinduced inflammation and indomethacininduced gastric ulceration. Cell. 1995 Nov 3;83(3):483-92. doi: 10.1016/00928674(95)90126-4. PMID: 8521478.

38. Brown NL, Alvi SA, Elder MG, Bennett PR, Sullivan MH. A spontaneous induction of fetal membrane prostaglandin production precedes clinical labour. J Endocrinol. 1998 May;157(2):R1-6. doi: 10.1677/joe.0.157r001. PMID: 9659298.

39. McAdam BF, Catella-Lawson F, Mardini IA, Kapoor S, Lawson JA, FitzGerald GA. Systemic biosynthesis of prostacyclin by cyclooxygenase (COX)-2: the human pharmacology of a selective inhibitor of COX2. Proc Natl Acad Sci U S A. 1999 Jan 5;96(1):272-7. doi: 10.1073/pnas.96.1.272. Erratum in: Proc Natl Acad Sci U S A 1999 May 11;96(10):5890. PMID: 9874808; PMCID: PMC15129.

40. Topper JN, Cai J, Falb D, Gimbrone MA Jr. Identification of vascular endothelial genes differentially responsive to fluid mechanical stimuli: cyclooxygenase-2, manganese superoxide dismutase, and endothelial cell nitric oxide synthase are selectively upregulated by steady laminar shear stress. Proc Natl Acad Sci U S A. 1996 Sep 17;93(19):10417-22. doi: 10.1073/pnas.93.19.10417. PMID: 8816815; PMCID: PMC38399.

41. Mitchell JA, Akarasereenont P, Thiemermann C, Flower RJ, Vane JR. Selectivity of nonsteroidal antiinflammatory drugs as inhibitors of constitutive and inducible cyclooxygenase. Proc Natl Acad Sci U S A. 1993 Dec 15;90(24):11693-7. doi: 
10.1073/pnas.90.24.11693. PMID: 8265610; PMCID: PMC48050.

42. Meade EA, Smith WL, DeWitt DL. Differential inhibition of prostaglandin endoperoxide synthase (cyclooxygenase) isozymes by aspirin and other non-steroidal anti-inflammatory drugs. J Biol Chem. 1993 Mar 25;268(9):6610-4. PMID: 8454631.

43. Lanza FL. A review of gastric ulcer and gastroduodenal injury in normal volunteers receiving aspirin and other non-steroidal antiinflammatory drugs. Scand J Gastroenterol Suppl. 1989;163:24-31. doi: 10.3109/00365528909091171. PMID: 2683026.

44. Vane JR, Botting RM. Mechanism of action of aspirin-like drugs. Semin Arthritis Rheum. 1997 Jun;26(6 Suppl 1):2-10. doi: 10.1016/s0049-0172(97)80046-7. PMID: 9219313.

45. Thun MJ, Namboodiri MM, Heath CW Jr. Aspirin use and reduced risk of fatal colon cancer. N Engl J Med. 1991 Dec 5;325(23):1593-6. doi: 10.1056/NEJM199112053252301. PMID: 1669840.

46. Luk GD. Prevention of gastrointestinal cancer-the potential role of NSAIDs in colorectal cancer. Schweiz Med Wochenschr. 1996 May 11;126(19):801-12. PMID: 8693304.

47. Gustafson-Svard C, Lilja I, Hallbook 0 , Sjodahl R. Cyclooxygenase-I and cyclooxygenase-2 gene expression in human colorectal adenocarcinomas and in azoxymethane induced colonic tumours in rats. Gut. 1996; 38:79-84

48. Kutchera W, Jones DA, Matsunami N, Groden J, McIntyre TM, Zimmerman GA, White RL, Prescott SM. Prostaglandin H synthase 2 is expressed abnormally in human colon cancer: evidence for a transcriptional effect. Proc Natl Acad Sci U S A. 1996 May 14;93(10):481620. doi: 10.1073/pnas.93.10.4816. PMID: 8643486; PMCID: PMC39362.

49. McGeer PL, McGeer EG. The inflammatory response system of brain: implications for therapy of Alzheimer and other neurodegenerative diseases. Brain Res Brain Res Rev. 1995 Sep;21(2):195-218. doi: 10.1016/0165-0173(95)00011-9. PMID: 8866675.

50. Breitner JC. The role of anti-inflammatory drugs in the prevention and treatment of Alzheimer's disease. Annu Rev Med. 1996;47:401-11. doi: 10.1146/annurev.med.47.1.401. PMID: 8712791.

51. Cochran FR, Vitek MP. Neuroinflammatory mechanisms in Alzheimer's disease: new opportunities for drug discovery. Expert Opin Invest Drugs. 1996; 5:449-455

52. Pasinetti GM, Aisen PS. Cyclooxygenase-2 expression is increased in frontal cortex of Alzheimer's disease brain. Neuroscience. 1998 Nov;87(2):319-24. doi: 10.1016/s03064522(98)00218-8. PMID: 9740394. 